Int. J. Dev. Biol. 51: 701-706 (2007)

doi: $10.1387 / \mathrm{ijdb} .072293 \mathrm{mk}$

Original Article

\title{
Centroid, a novel putative DEAD-box RNA helicase maternal mRNA, is localized in the mitochondrial cloud in Xenopus laevis oocytes
}

\author{
MALGORZATA KLOC $*, 1$ and AGNES P. CHAN ${ }^{2}$ \\ ${ }^{1}$ Department of Biochemistry and Molecular Biology, The University of Texas M.D. Anderson Cancer Center, Houston, Texas and \\ ${ }^{2}$ The Institute for Genomic Research, Rockville, Maryland, USA
}

\begin{abstract}
In Xenopus species, the early stages of oogenesis take place in the developing tadpole ovary when the oocytes are in a period critical for the organization of the germ plasm (believed to be a determinant of germ-cell fate) and the initial stages of localization of RNAs involved in germ plasm functions. We constructed a cDNA library from the ovaries of stage 64 Xenopus tadpoles with the idea that it will be enriched for oogonia and pre-stage I and stage I oocytes and thus, RNAs involved in oocyte development and germ plasm formation and function. From this cDNA library, we cloned a new maternal localized mRNA which we named centroid. This RNA codes for the protein belonging to the DEAD-box RNA helicase family. Some of the members of this protein family are components of the messenger ribonucleoprotein (mRNP) particles stored in the germ plasm in oocytes of Xenopus, Drosophila and Caenorhabditis species and are believed to play a role in translational activation of stored mRNPs and sorting of mRNPs into the germ plasm. We found that centroid mRNA is localized in Xenopus oocytes by a combination of early and late pathways, a pattern of localization that is very similar to the intermediate pathway localization of fatvg mRNA, another germ-plasm-localized RNA in Xenopus oocytes. Also, centroid mRNA is present in the mitochondrial cloud and in the germ plasm at the surface of germinal granules. This suggests that centroid is involved in the regulation of germ plasm-stored mRNPs and/or germ plasm function.
\end{abstract}

KEY WORDS: DEAD-box RNA helicase, localized RNA, germ plasm, oocyte, Xenopus

\section{Introduction}

Localized RNAs are known to play important roles in the establishment of asymmetry in a wide variety of systems from yeast to mammals (Bashirullah et al., 1998; Jansen, 2001; King et al., 1999; Kloc et al., 2001a, 2002b; Palacios and Johnston, 2001). In the frog Xenopus laevis, subsets of RNAs are localized to the animal and vegetal poles of oocytes (Forristall et al., 1995; King et al., 1999; Kloc et al., 2001a, 2002b; Kloc and Etkin, 1995). RNAs are localized to the vegetal pole of Xenopusoocyte by three different pathways. First, the early or METRO pathway uses the mitochondrial cloud (Balbiani body) to deliver RNAs such as Xlsirts, Xcat2 (related to the Nos/Vasa DEAD-box family; AspGlu-Ala-Asp, D-E-A-D; hence the family name), Xpat, Xwnt 11, Xdazl, the DEAD-box RNA helicase DEADSouth and germinal granules (collectively called the germ plasm and believed to be a germ-cell determinant) to the vegetal pole in early oogenesis. Second, the late pathway operates in late oogenesis and uses microtubules and molecular motors to deliver RNAs such as Vg1 and VegT to the vegetal pole of the oocyte (Forristall et al., 1995; Kloc and Etkin, 1995). Third, the intermediate pathway uses a combination of early and late pathways to deliver RNAs such as fatvg to the vegetal pole of the oocyte (Chan et al., 1999, 2001).

Studies have shown that vegetally localized mRNAs Vg1, VegT and Xwnt 11 are determinants of mesoderm and endoderm fate as well as the left-right axis in the embryo (Joseph and Melton, 1998; Rebagliati etal., 1985; Stennard etal., 1996; Xanthos etal., 2001; Zhang et al., 1998; Zhang and King, 1996). Most recently, we showed that the localized RNAs XIsirts and VegT in Xenopus play a structural role in maintaining the integrity of the cytoskeleton of the vegetal cortex (Kloc et al., 2005; Kloc et al., 2007). Other vegetally localized mRNAs in Xenopus species, such as Xcat2, Xdazl and fatvg, are believed to play roles in germ-cell

Abbreviations used in this paper: $\mathrm{mRNP}$, messenger ribonucleoprotein; ORF, open reading frame; UTR, untranslated region. 
determination or migration (Houston and King, 2000a, 2000b; Chan et al., 2001, 2007), whereas Xpat may be involved in the organization of the germ plasm, perhaps playing a role similar to that of oskar in Drosophila species (Hudson and Woodland, 1998). Thus, a substantial number of localized transcripts clearly play critical roles in a wide variety of cellular and developmental processes and the discovery of novel localized transcripts will undoubtedly lead to a greater understanding of how oogenesis, development and many other cellular processes are regulated.

\section{Results}

We constructed a cDNA library from the ovaries of stage 64 Xenopustadpoles with the idea that it will be enriched for oogonia and pre-stage I and stage I oocytes. In Xenopus, the early stages of oogenesis take place in the developing tadpole ovary. Each oogonium undergoes four mitotic divisions with incomplete cytokinesis, giving rise to a cluster (nest) of 16 pre-stage I oocytes (connected by cytoplasmic bridges) that enter the prophase of meiosis (Kloc et al., 2004). Subsequently, in the ovaries of froglets, the oocytes become separated and surrounded by ingrowing follicular cells and cytoplasmic bridges connecting the oocytes disintegrate; in the ovaries of adult frogs, the oocytes enter the phase of growth and accumulation of yolk (stage I-VI oocytes).

The prominent structure in pre-stage I and stage I-II oocytes is the mitochondrial cloud, which is located in the vicinity of the oocyte nucleus (Kloc et al., 2004). The main body of the mitochondrial cloud is composed of mitochondria and its vegetal apex contains germ plasm. In the tadpole ovary, the oocytes are in a period critical for the organization of the germ plasm and the initial stages of localization of germ plasm RNAs such as Xcat2 (Kloc et al., 1998, 2002a, 2004). In prestage I and early stage I oocytes, the germ plasm contains the mitochondrial cement, which is located between mitochondria and originates from the perinuclear nuage. The mitochondrial cement is the immediate precursor of granulofibrillar material (GFM), which ultimately forms the "mature" germinal granules present in stage I and older oocytes (Bilinski et al., 2004; Kloc et al., 2004). Therefore, we constructed the cDNA library described above with the intent of identifying RNAs critical for these processes. After isolation of individual clones, we determined the patterns of localization of their cognate RNAs in different-stage oocytes (pre-stage I to stage VI) using in situhybridization.

We isolated a total of 91 individual clones. Of these clones, 27 were positive by in situ hybridization in nest-stage (pre-stage I) oocytes: 8 clones gave a positive signal in the mitochondrial cloud and 19 clones gave a positive signal in the cytoplasm. In stage I-VI oocytes, we found 27 positive clones: 11 clones, including the clone named centroid described below, gave a positive signal in both the mitochondrial cloud and vegetal cortex and 16 clones gave a positive signal in the cytoplasm. From the screen we identified 10 new localized transcripts. We sequenced all of the clones showing definite localization patterns and analyzed them for homology using database searches (unpublished data).

Fig. 1. Centroid nucleotide sequence and deduced amino acid sequence. (A) Nucleotide sequence of the centroid cDNA clone. The whole clone was 1,990 bp long with a 614-bp-long 5' untranslated region (UTR), 765-bp-long open reading frame (ORF, marked in red) and 611-bp-long 3' UTR. (B) Deduced amino acid sequence of centroid protein showing motifs (boxed) common to DEAD-box RNA helicases. (C) Comparison of the amino acid composition of DEAD-box RNA helicase consensus motifs and centroid. Motifs $Q$, I (Walker A), II (Walker B) and VI are involved in ATP binding and hydrolysis; motifs Ia, Ib, IV and V are involved in RNA binding; and motif III is involved in RNA-induced conformational changes (Cordin et al., 2006; Heung and Del Poeta, 2005).

\section{Centroid is a member of the DEAD-box RNA helicase protein family}

One of the cDNA clones that we isolated from the tadpole ovary cDNA library was 1,990 bp long (GenBank accession number 

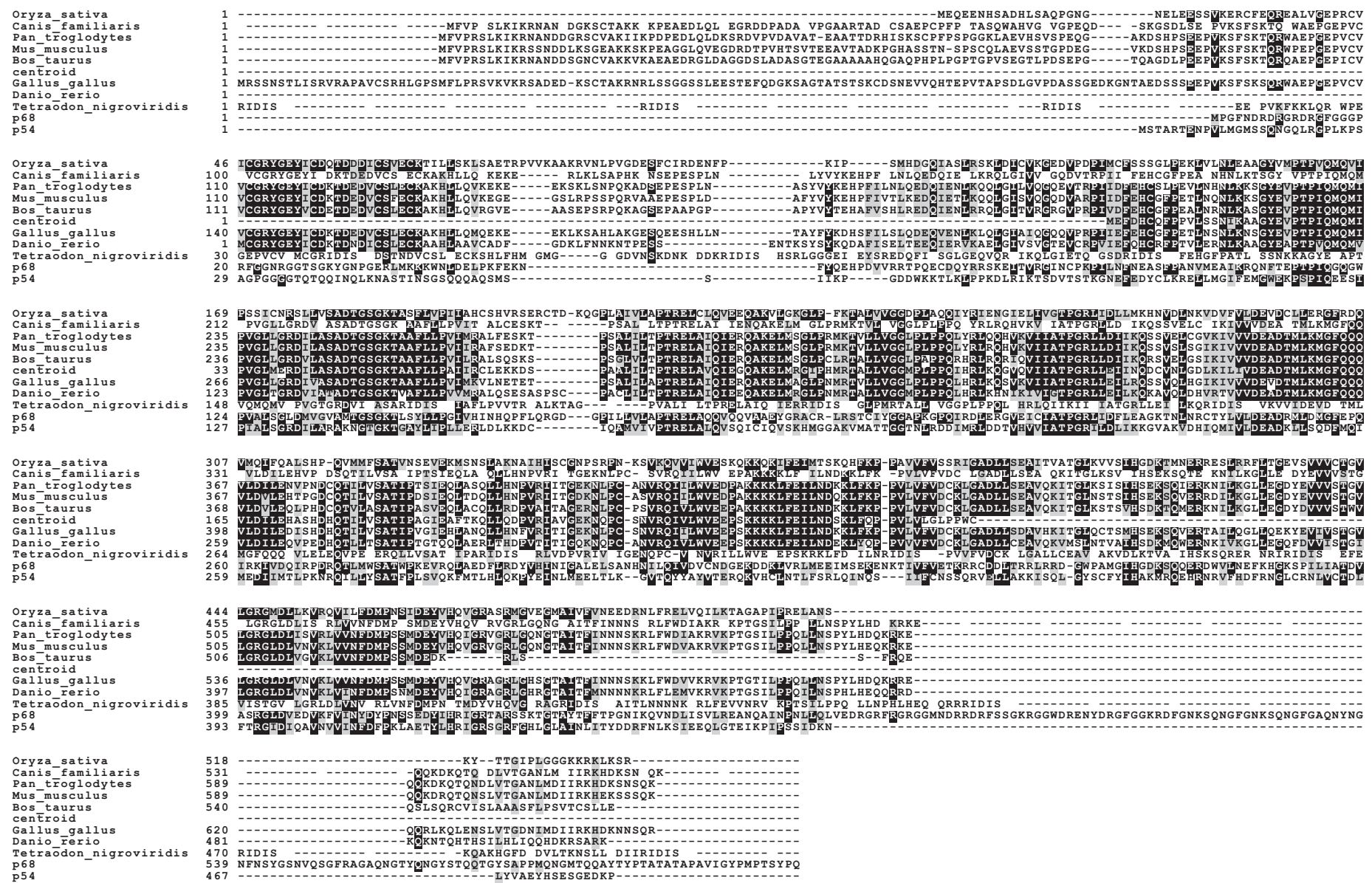

Fig. 2. Alignment of the centroid amino acid sequence and related DEAD-box RNA helicase proteins. A BlastPsearch was performed using centroid protein sequence against the $\mathrm{NCBI}$ non redundant peptide database. Nine representative protein sequences from a variety of organisms (including mammals and plants) were selected from among the top search hits to assess sequence conservation by multiple alignments. Two Xenopus DEAD-box proteins (Xp54 and p68) were also included in the alignment for comparison. The multiple sequence alignments of the amino acid sequences were generated using ClustalW (http://searchlauncher.bcm.tmc.edu/multi-align/multi-align.html) followed by BOXSHADE (http://Www.ch.embnet.org/ software/BOX_form.html). The black and gray shaded boxes indicate identical and similar amino acid residues, respectively, in a given column.

843804; Fig. 1A) and contained a 765-bp-long open reading frame (ORF). Translation of the ORF showed a conceptual protein of 254 amino acids containing a DEAD-box motif (Figs. 1B and $1 \mathrm{C}$ ). We performed a database search using the Basic Local Assignment Search Tool (National Center for Biotechnology Information) that showed extensive homology between this clone and other vertebrate and invertebrate DEAD-box RNA helicases (Fig. 2). Specifically, we found $75 \%$ identity of this clone with Gallus gallus (GenBank accession number XM-422189; unpublished data), 73\% identity with Canis familiaris (GenBank accession number NW-876323; unpublished data), 72\% identity with Bos taurus (GenBank accession number XM-592818.2; unpublished data) and Mus musculus (Carninci and Hayashizaki, 1999), $68 \%$ identity with Danio rerio (Strausberg et al., 2002), 37\% identity with chordate p68 (Seufert et al., 2000) and 36\% identity with Xenopus p54 (Ladomery et al., 1997) DEAD box RNA helicases (Fig. 2). Analysis of the centroid protein sequence showed the presence of six of nine conserved motifs-Q, I, la, lb, II and III—characteristic of DEAD-box RNA helicases (Fig. 1C).
Motifs Q, I and II are known to function in ATP binding and hydrolysis, motifs la and $\mathrm{lb}$ are known to function in RNA binding and motif III is known to function in ATP-induced conformational changes (Cordin et al., 2006, Heung and Del Poeta, 2005).

\section{Centroid $m R N A$ is localized by the intermediate pathway and is a component of germ plasm}

To determine the localization pattern of centroid RNA, we performed whole mount in situhybridization and in situhybridization on sections of different-stage oocytes for light and electron microscopy. Light microscopy showed that in pre-stage 1 oocytes, centroid RNA was dispersed throughout the cytoplasm but was not present in the main mitochondrial cloud and secondary clouds (Fig. 3). In stage l oocytes, centroid RNA was present in the center of the mitochondrial cloud; starting at late stage I, it colocalized with the germ plasm first at the vegetal tip of the mitochondrial cloud and then in the mitochondrial cloud fragments at the oocyte vegetal cortex (Fig. 3). This indicated that centroid mRNA is localized by a combination of early and late 

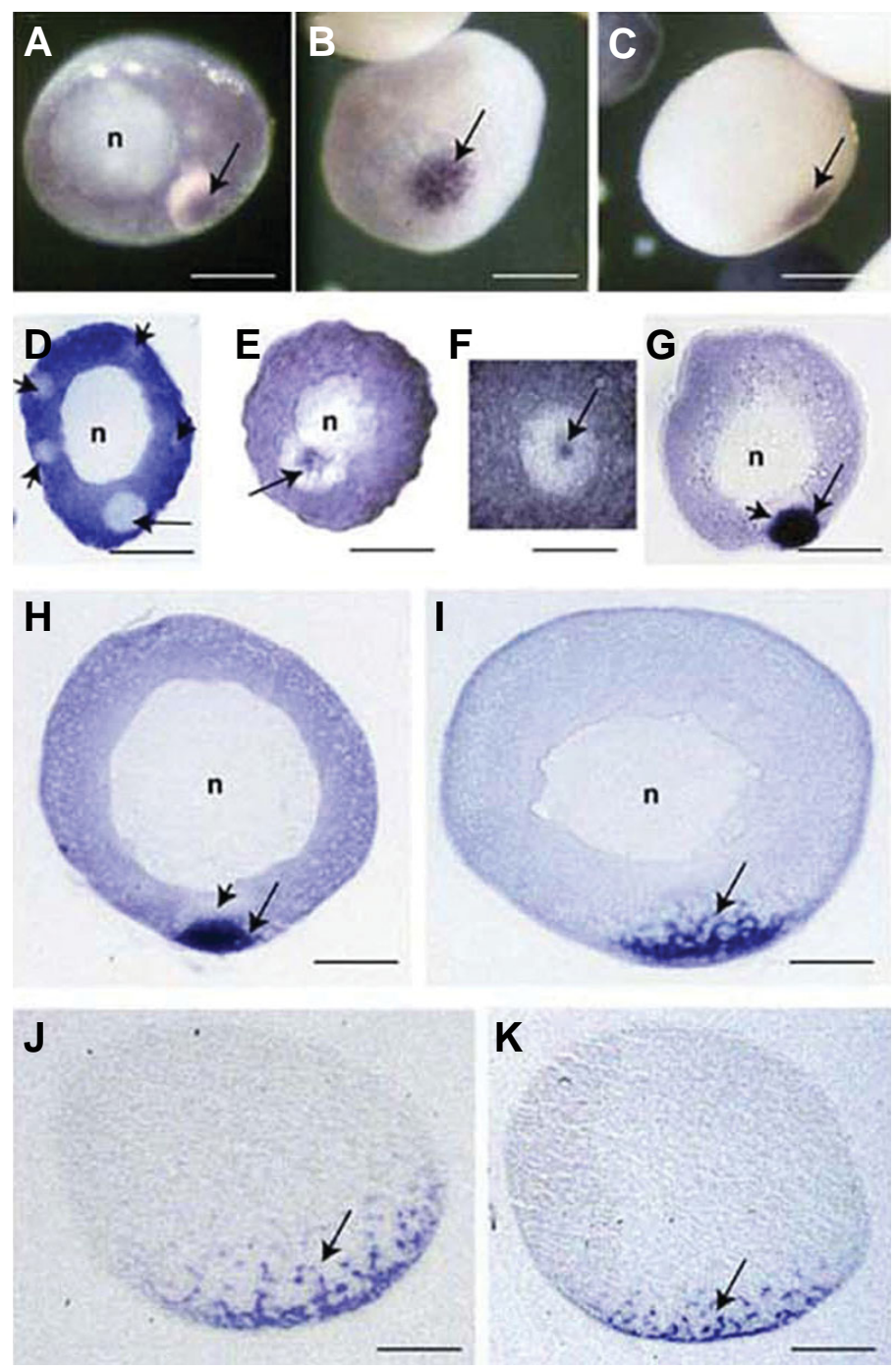

pathways, a pattern of localization that is very similar to the intermediate pathway localization of fatvg mRNA, another germplasm-localized RNA in Xenopus oocytes (Chan et al., 1999, 2001, 2007).

Electron microscopy analysis of centroid mRNA localization showed that centroid mRNA is absent from the mitochondrial cement in pre-stage I oocytes (Fig. 4). We calculated the number of silver grains present in mitochondrial cement and surrounding cytoplasm in 20 samples. We found no (zero) grains in the mitochondrial cement and on average 9.75 (s. d. 3.45) grains in the matrix region of mitochondrial cloud. In early stage I oocytes centroid mRNA was visible in the vicinity of but not on the germinal granules (on average 2.7 grains with $\mathrm{s}$. $\mathrm{d}$. $=2.1$ in the vicinity of germinal granules) and subsequently starting at late stage I/ early stage II oocytes it was present at the periphery of the germinal granules (on average 3.2 grains with $\mathrm{s}$. $d$. $=1.58$ on the periphery of each granule; Fig. 4).

\section{Discussion}

We cloned a new maternal localized mRNA that belongs to the DEAD-box RNA helicase family of proteins. These proteins are
Fig. 3. Centroid mRNA localization in Xenopus oocytes. (A-C) Whole mount in situ hybridization showing localization of centroid mRNA (arrows) in the mitochondrial cloud in a stage 1 oocyte (A) and in the apex of the vegetal cortex in a stage // oocyte (B) and a stage III oocyte (C). (DJ) Sections of whole mount in situ hybridization showing localization of centroid mRNA in oocytes at different stages. (D) In a pre-stage l oocyte, centroid mRNA is uniformly dispersed in the cytoplasm but excluded from the mitochondrial cloud (long arrow) and secondary clouds (short arrows). (E,F) In a stage l oocyte, centroid mRNA (arrow) is located in the center of the mitochondrial cloud. Panel (F) shows the high magnification of the mitochondrial cloud (white sphere) with centrally located centroid mRNA (arrow). (G,H) In late stage I/early stage /I and stage // oocytes, centroid $m R N A$ is limited to the vegetal tip of the mitochondrial cloud (colocalizing with the germ plasm [long arrow]) and is excluded from the apical part of the mitochondrial cloud (short arrows). (I-K) Stage III, early stage IV and stage IV oocytes showing localization of centroid mRNA in the islands of a dispersing mitochondrial cloud (arrows). n, nucleus. Scale bars are equal to $56 \mu \mathrm{m}$ in (A), $90 \mu \mathrm{m}$ in (B, G), $100 \mu \mathrm{m}$ in (C), $70 \mu \mathrm{m}$ in (D), $75 \mu \mathrm{m}$ in (E), $65 \mu \mathrm{m}$ in (F), $86 \mu \mathrm{m}$ in (H), $80 \mu \mathrm{m}$ in (I) and $100 \mu \mathrm{m}$ in $(\mathrm{J}, \mathrm{K})$.

ATP-dependent enzymes involved in many aspects of RNA metabolism such as transcription, RNA splicing, ribosome biogenesis, translation initiation and RNA transport and degradation and are found in all eukaryotes and most prokaryotes (Cordin et al., 2006; Heung and Del Poeta, 2005). Members of this family share conserved motifs that play a role in ATP binding and hydrolysis, RNA binding and RNA-induced conformational changes. Comparison of the amino acid composition of DEADbox RNA helicase consensus motifs and centroid showed that centroid contains motifs Q, I (Walker A), II (Walker B), which are involved in ATP binding and hydrolysis, motifs la, lb involved in RNA binding and motif III which is involved in RNA-induced conformational changes (Cordin et al., 2006; Heung and Del Poeta, 2005). The presence in the centroid of the motifs $Q$ and IIII suggests that this protein is involved in the ssRNA binding, ATP hydrolysis and it may possess helicase activity. Interestingly, centroid lacks the motif IV, V and VI, which are present in DEADbox RNA helicase consensus sequence. So far the function of motif IV is poorly understood but it was suggested that it may be involved in ssRNA binding and that has a functional connection to motif $\mathrm{V}$ involved in ATP hydrolysis (Cordin et al., 2006). Motif VI has been shown to participate in RNA binding and ATPase activity (Cordin et al., 2006). The DEAD-box RNA helicases are the multifunctional molecules and their activities depend on the communication and interaction between multifunctional motifs. Only future functional studies will be able to show how the lack of motif IV-VI influences the centroid function in comparison with other known DEAD-box helicases. Some of the members of this protein family, such as the DEAD-box RNA helicase p54 (Ladomery et al., 1997; Weston and Sommerville, 2006), are components of the messenger ribonucleoprotein (mRNP) particles stored in the germ plasm in oocytes of Xenopus, Drosophilaand Caenorhabditis species and are believed to play a role in translational activation of stored mRNPs and sorting of mRNPs into the germ plasm (Bilinski et al., 2004; Cordin etal., 2006; Weston and Sommerville, 2006).

Previously, we described the presence of two DEAD-box RNA helicases DEADSouth (Bilinski et al., 2004; Komiya et al., 1994; MacArthur et al., 2000) and vasa-like XVLG1 in the germ plasm in Xenopus oocytes (Bilinski et al., 2004). DEADSouth mRNA is 


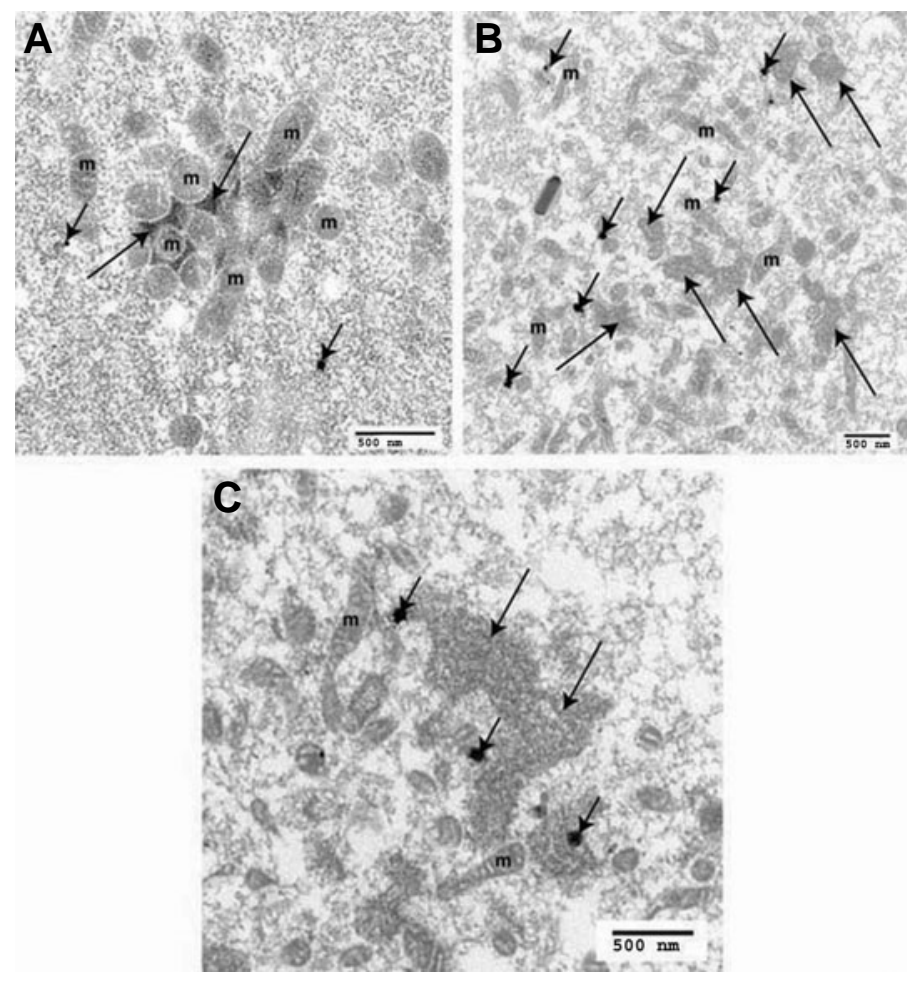

Fig. 4. Electron microscopy analysis of centroid mRNA localization in the germ plasm of Xenopus oocytes. (A) Fragment of the mitochondrial cloud in a pre-stage l oocyte hybridized with a centroid anti-sense RNA probe, labeled with nanogold and silver-enhanced showing the mitochondrial cement (long arrows) located between the mitochondria. Centroid mRNA (short arrows) is present in the mitochondrial cloud but excluded from the mitochondrial cement. (B,C) Fragment of the mitochondrial cloud from stage 2 oocytes showing centroid mRNA (short arrows) located in the vicinity (B) and at the periphery (C) of the germinal granules (long arrows). $m$, mitochondria.

present at the surface of GFM and germinal granules but absent from nuage and mitochondrial cement. In contrast, XVLG1 mRNA is absent from germinal granules and GFM, but XVLG1 protein is present in nuage and mitochondrial cement (Bilinski et al., 2004). The fact that centroid mRNA is also present at the surface of germinal granules in Xenopus oocytes suggests its involvement in the regulation of germ plasm-stored $\mathrm{mRNPs}$ and/or germ plasm function. In addition, the fact that different DEAD-box RNA helicases are present in germinal granules at different stages of formation (nuage, GFM, mature germinal granules) suggests that their function is temporarily regulated during the formation and "maturation" of the germ plasm. However, determination of the role of centroid and the precise role of other germ-plasm-localized DEAD-box RNA helicases in germ plasm function will require further functional study.

\section{Materials and Methods}

\section{Construction of the stage 64 tadpole cDNA library (nest library)}

Several dozen ovaries ( $300 \mathrm{mg}$ of ovarian tissue) were collected from $4 \mathrm{~cm}$-long froglets into RNAlater solution (Ambion). Total RNA was prepared using an RNAqueous kit (Ambion) and poly(A+) RNA was isolated using an Oligotex RNA mini kit (Qiagen) according to the manufacturer's protocol. A directional cDNA library was prepared using poly $(A+)$ RNA and the SuperScript plasmid system with pSPORT1 plasmid (Gibco BRL). In short, $4 \mu \mathrm{g}$ of poly (A) RNA, TTTTTT Not primer adapter and Superscriptll reverse transcriptase were used to introduce directionality and to make first-strand cDNA. Subsequently, the Escherichia coliligase, DNA polymerase I and T4 polymerase were used to make second-strand and double-strand cDNA. The resulting double-strand cDNA was Sal-adapted with T4 DNA ligase. After subsequent digestion with Not, the cDNA with Not/Sal termini was size-fractionated using column chromatography. Fractions 1-12 were pooled and precipitated and the cDNA was ligated to a Nol/Sal-cut pSPORT1 vector. Vectorligated $\mathrm{cDNA}$ was introduced by transformation into $E$. coli(XI blue) cells. Transformed bacteria were plated on ampicillin plates and colonies from 10 plates were scraped into LB medium and frozen in glycerol at $-80^{\circ} \mathrm{C}$. This served as a library stock for further screening using in situhybridization.

\section{Screening of the nest library}

The nest library was plated on LB ampicillin plates. Plasmid DNA from single colonies was purified using a plasmid purification kit (Qiagen). DNA from each colony was linearized with $S a l$ and antisense digoxigeninlabeled RNA probes were synthesized in vitro using Sp6 RNA polymerase. Froglet ovaries containing nest-stage and early pre-stage I oocytes and stage I-VI oocytes from large frog ovaries were defolliculated with collagenase, fixed in MEMFA and hybridized whole mount with RNA probes according to a protocol described previously (Kloc and Etkin, 1995). Anti-digoxigenin antibody conjugated with alkaline phosphatase and a BCIP/NBT substrate was used to detect (by color reaction) the hybridization signal.

Oocytes that showed positive signal were photographed as whole mounts and subsequently embedded in paraplast and sectioned at 10 $\mu \mathrm{m}$. The sections were deparaffinated in HistoClear (National Diagnostics), mounted in Permount (Sigma) and photographed under a Nikon microscope.

\section{Whole mount in situ hybridization for electron microscopy}

Whole mount in situ hybridization for electron microscopy was performed exactly as described previously (Kloc et al., 2001b). In short, oocytes were fixed in $4 \%$ formaldehyde, $0.1 \%$ glutaraldehyde, $100 \mathrm{mM}$ $\mathrm{KCl}, 3 \mathrm{mM} \mathrm{MgCl}$, $10 \mathrm{mM} \mathrm{HEPES}, 150 \mathrm{mM}$ sucrose and $0.1 \%$ Triton $\mathrm{X}$ 100, $\mathrm{pH}$ 7.6. After fixation and washing, oocytes were treated for $7 \mathrm{~min}$ with $10 \mu \mathrm{g} / \mathrm{ml}$ proteinase $\mathrm{K}$ in PBS- $0.1 \%$ Tween 20 and hybridized overnight at $50^{\circ} \mathrm{C}$ with a digoxigenin-labeled antisense RNA probe (see above). After washing, oocytes were incubated overnight at $4^{\circ} \mathrm{C}$ with a 1:30 dilution of anti-DIG $0.8 \mathrm{~nm}$ gold (Roche) in G2 buffer (Roche). After intensive washing in PBS-Tween 20, oocytes were silver-enhanced and processed for embedding and sectioning for electron microscopy as described previously (Kloc et al., 2001b). The sections were examined in a JEOL 1200EX transmission electron microscope.

\section{Acknowledgements}

EM analysis was supported by Cancer Center Support (Core) Grant CA 16672 from the National Institutes of Health for The University of Texas M. D. Anderson Cancer Center High Resolution Electron Microscopy Facility We would like to thank Kenneth Dunner, Jr., for his electron microscopy work.

\section{References}

BASHIRULLAH, A., COOPERSTOCK, R. L., LIPSHITZ, H. D. (1998). RNA localization in development. Annu Rev Biochem 67:335-94.

BILINSKI, S. M., JAGLARZ, M. K., SZYMANSKA, B., ETKIN, L. D., KLOC, M. (2004). Sm proteins, the constituents of the spliceosome, are components of nuage and mitochondrial cement in Xenopus oocytes. Exp. Cell Res. 299: 171178. 
CARNINCI, P. and HAYASHIZAKI, Y. (1999). High-efficiency full-length cDNA cloning. Methods Enzymo/303: 19-44.

CHAN, A. P., KLOC, M., BILINSKI, S., ETKIN, L. D. (2001). The vegetally localized mRNA fatvg is associated with the germ plasm in the early embryo and is later expressed in the fat body. Mech. Dev. 100: 137-140.

CHAN, A. P., KLOC, M., ETKIN, L. D. (1999). fatvg encodes a new localized RNA that uses a 25-nucleotide element (FVLE1) to localize to the vegetal cortex of Xenopus oocytes. Development 126: 4943-4953.

CHAN, A. P., KLOC, M., LARABELL, C., LEGROS, M., ETKIN, L. D. (2007). The maternally localized RNA fatvg is required for cortical rotation and germ cell formation. Mech. Dev. 124: 350-363

CORDIN, O., BANROQUES, J., TANNER, N. K., LINDER, P. (2006). The DEADbox protein family of RNA helicases. Gene. 367: 17-37.

FORRISTALL, C., PONDEL, M., CHEN, L. and KING, M. L. (1995). Patterns of localization and cytoskeletal association of two vegetally localized RNAs, Vg1 and Xcat-2. Development 121: 201-208.

HEUNG, L. J. and DEL POETA, M. (2005). Unlocking the DEAD-box: A key to cryptococcal virulence? J. Clin. Invest. 115: 593-595.

HOUSTON, D. W. AND KING, M. L. (2000a). A critical role for Xdazl, a germ plasmlocalized RNA, in the differentiation of primordial germ cells in Xenopus. Development 127: 447-456.

HOUSTON, D. W. AND KING, M. L. (2000b). Germ plasm and molecular determinants of germ cell fate. Curr. Top. Dev. Biol. 50:155-181.

HUDSON, C. and WOODLAND, H. R. (1998). Xpat, a gene expressed specifically in germ plasm and primordial germ cells of Xenopus laevis. Mech. Dev. 73: 159168.

JANSEN, R. P. (2001). mRNA localization: Message on the move. Nat. Rev. Mol. Cell. Biol. 2: 247-256.

JOSEPH, E. M. AND MELTON, D. A. (1998). Mutant Vg1 ligands disrupt endoderm and mesoderm formation in Xenopus embryos. Development 125:2677-2685.

KING, M. L., ZHOU, Y. and BUBUNENKO, M. (1999). Polarizing genetic information in the egg: RNA localization in the frog oocyte. BioEssays 21: 546-557.

KLOC, M., BILINSKI, S., CHAN, A. P., ALLEN, L. H., ZEARFOSS, N. R. and ETKIN, L. D. (2001a). RNA localization and germ cell determination in Xenopus. Int. Rev. Cytol. 203: 63-91.

KLOC, M., BILINSKI, S., CHAN, A. P., ETKIN, L. D. (2001b). Mitochondrial ribosomal RNA in the germinal granules in Xenopus embryos revisited. Differentiation 67: 80-83.

KLOC, M., BILINSKI, S., DOUGHERTY, M. T., BREY, E. M. and ETKIN, L. D. (2004). Formation, architecture and polarity of female germline cyst in Xenopus. Dev. Biol. 266: 43-61.

KLOC, M., BILINSKI, S., DOUGHERTY, M. T. (2007). Organization of cytokeratin cytoskeleton and germ plasm in the vegetal cortex of Xenopus laevis oocytes depends on coding and non-coding RNAs: three-dimensional and ultrastructural analysis. Exp. Cell Res. 313: 1639-1651.

KLOC, M., DOUGHERTY, M. T., BILINSKI, S., CHAN, A. P., BREY, E., KING, M. L., PATRICK JR. C. W. and ETKIN, L. D. (2002a). Three-dimensional ultrastructural analysis of RNA distribution within germinal granules of Xenopus. Dev. Biol. 241: 79-93.

KLOC, M. AND ETKIN, L. D. (1995). Two distinct pathways for the localization of
RNAs at the vegetal cortex in Xenopus oocytes. Development 121: 287-297.

KLOC, M., LARABELL, C., CHAN, A. P. and ETKIN. L. D. (1998). Contribution of METRO pathway localized molecules to the organization of the germ cell lineage. Mech. Dev. 75: 81-93.

KLOC, M., WILK, K., VARGAS, D., SHIRATO Y., BILINSKI, S., ETKIN L.D. (2005). Potential structural role of non-coding and coding RNAs in the organization of the cytoskeleton at the vegetal cortex of Xenopus oocytes. Development, 132: 3445-3457.

KLOC, M., ZEARFOSS, N. R. and ETKIN, L. D. (2002b). Mechanisms of subcellular mRNA localization. Cel/108: 533-544.

KOMIYA, T., ITOH, K., IKENISHI, K., FURUSAWA, M. (1994). Isolation and characterization of a novel gene of the DEAD box protein family which is specifically expressed in germ cells of Xenopus laevis. Dev. Biol. 162: 354-363.

LADOMERY, M., WADE, E., SOMMERVILLE, J. (1997). Xp54, the Xenopus homologue of human RNA helicase p54, is an integral component of stored mRNP particles in oocytes. Nucleic Acids Res. 25: 965-973.

MACARTHUR, H., HOUSTON, D. W., BUBUNENKO, M., MOSQUERA, L., KING, M. L. (2000). DEADSouth is a germ plasm specific DEAD-box RNA helicase in Xenopus related to elF4A. Mech. Dev. 95: 291-295.

PALACIOS, I. M. and ST. JOHNSTON, D. (2001). Getting the message across: The intracellular localization of mRNA in higher eukaryotes. Annu. Rev. Cell. Dev. Biol. 17: 569-614.

REBAGLIATI, M. R., WEEKS, D. L., HARVEY, R. P. AND MELTON, D. A. (1985) Identification and cloning of localized maternal RNAs from Xenopus eggs. Cell 42: 769-777.

SEUFERT, D. W., KOS, R., ERICKSON, C. A, SWALLA, B. J. (2000) p68, a DEADbox RNA helicase, is expressed in chordate embryo neural and mesodermal tissues. J. Exp. Zool. 288: 193-204.

STENNARD, F., CARNAC, G. AND GURDON, J. B. (1996). The Xenopus T-box gene, Antipodean, encodes a vegetally localised maternal mRNA and can trigger mesoderm formation. Development 122: 4179-4188.

STRAUSBERG, R.L., FEINGOLD, E.A., GROUSE, L.H., DERGE, J.G. et al., (2002). Generation and initial analysis of more than 15,000 full-length human and mouse cDNA sequences. Proc. Natl. Acad. Sci. USA. 99: 16899-16903.

WESTON, A., SOMMERVILLE, J. (2006). Xp54 and related (DDX6-like) RNA helicases: Roles in messenger RNP assembly, translation regulation and RNA degradation. Nucleic Acids Res. 34: 3082-3094.

XANTHOS, J. B., KOFRON, M., WYLIE, C. and HEASMAN, J. (2001). Maternal VegT is the initiator of a molecular network specifying endoderm in Xenopus laevis. Development 128: 167-180.

ZHANG, J., HOUSTON, D. W., KING, M. L., PAYNE, C., WYLIE, C. AND HEASMAN, J. (1998). The role of maternal VegT in establishing the primary germ layers in Xenopus embryos. Cel/94: 515-524.

ZHANG, J. and KING, M. L. (1996). Xenopus VegT RNA is localized to the vegetal cortex during oogenesis and encodes a novel T-box transcription factor involved in mesodermal patterning. Development 122: 4119-4129.

Published Online: 4th October 2007 
Related, previously published Int. J. Dev. Biol. articles

Germ-plasm specification and germline development in the parthenogenetic pea aphid Acyrthosiphon pisum: Vasa and Nanos as markers

Chun-che Chang, Wen-chih Lee, Charles E. Cook, Gee-way Lin and Tschining Chang

Int. J. Dev. Biol. (2006) 50: 413-421

Delivery of germinal granules and localized RNAs via the messenger transport organizer pathway to the vegetal cortex of Xenopus oocytes occurs through directional expansion of the mitochondrial cloud

Katarzyna Wilk, Szczepan Bilinski, Matthew T. Dougherty and Malgorzata Kloc

Int. J. Dev. Biol. (2005) 49: 17-21

Xenopus oocyte maturation: cytoplasm alkalization is involved in germinal vesicle migration.

S Flament, E Browaeys, J L Rodeau, M Bertout and J P Vilain

Int. J. Dev. Biol. (1996) 40: 471-476 